\title{
«Quiso Dios» o «acordé y me determiné»: voluntad divina o libre albedrío de Cortés en la Segunda relación
}

\section{«It Pleased God» or «I Resolved and I Determined»: Divine Will or Free Will in Cortés' Second Letter}

\author{
Beatriz Gutiérrez Mueller \\ Benemérita Universidad Autónoma de Puebla \\ cuca599@hotmail.com \\ ORCID iD: http://orcid.org/0000-0001-7554-1838
}

\section{RESUMEN}

En distintas épocas en el mundo cristiano, como la que le tocó vivir a Cortés, se ha registrado una tensión entre la predeterminación de Dios, que obra a través de su Divina Providencia, y la voluntad del hombre: si se tocan o se distancian; si la renuncia de una implica el actuar de otra; si coexisten o se comprometen. Además, la historiografía cristiana hace distinciones en torno al providencialismo, cuando menos, en tres notables autores: Agustín y Paulo Orosio, de un lado y Tomás de Aquino, del otro. El presente trabajo analiza la mezcla de providencialismos empleados por Cortés en su Segunda relación (1520), en donde lo mismo ve señales divinas sobre hechos que presenció, como prevé triunfos futuros o decide por su cuenta. También, cómo se vale, ante su propio desconcierto de lo que no puede explicarse, de la propia retórica para persuadir al rey de España sobre la importancia de contar con su legitimación y financiación de la conquista de México, según se desprende por la fecha en que firmó la carta.

Palabras Clave: Providencia Divina; libre albedrío; Hernán Cortés; Segunda relación.

\begin{abstract}
At different times in the Christian world, such as the world that Cortes lived in, a tension has been registered between the predetermination of God, who works through His Divine Providence, and the will of man: if they touch or they are distanced; if the renunciation of one implies the action of another; if they coexist or if they are committed. Furthermore, Christian historiography makes distinctions around providentialism, at least among three notable authors: Augustine and Paulus Orosius in one hand, and Thomas Aquinas, in the other. This paper analyzes the mixture of providentialisms employed by Cortés in his Second letter (1520), where he himself sees divine signs of witnessed events, as well as he anticipates future triumphs, or he decides on his own. Moreover, in the face to his own bewilderment of what he cannot explain, he uses his
\end{abstract}


own rhetoric to persuade the king of Spain of the importance of having his legitimacy and funding to conquer Mexico, according to the letter's sign's date.

Key words: Divine Providence; Free Will; Hernán Cortés; Second Letter.

Hernán Cortés partió de Sanlúcar de Barrameda con rumbo a América y se asentó en Santo Domingo (1504), donde se convirtió en un próspero granjero hasta llegar a ejecutar las funciones de letrado y colono en su larga estancia caribeña. Siete años después, el gobernador de Cuba, Diego Velázquez, mandaba una expedición a República Dominicana, para una «cabalgada» contra sus «pacíficos indios», en la que fue incluido para, más adelante, volver a la agricultura pero, esta vez, en Baracoa ${ }^{1}$. Conforme supo, entre 1517 y 1518 que había un territorio más allá, sin saber su dimensión e importancia, cabildeó para ser nombrado capitán, y el 23 de octubre de 1518 se firmaron las capitulaciones de la expedición que estaba por iniciar. Tal tarea consistía en comerciar, explorar y espiar².

No creo posible, al igual que Prien (1996) que, para el inicio de su expedición, Cortés se mirara a sí mismo como un designado por Dios para emprender una «conquista» y menos, de la «Nueva España» o la «Nueva España del mar Océano», como le denomina en la Segunda relación. Imaginémoslo, tal vez, queriendo toparse con aquel gran imperio - del que pudo saber «de oídas», en el mejor de los casos - hallar oro, tesoros perdidos o nada más seguir una pulsación aventurera. De lo que no debe dudarse es que, conforme transcurrieron los hechos en los territorios que estaba por conocer, fue enterándose cada vez más acerca de la gran Tenochtitlán y, de forma progresiva, se fue reflejando en la escritura de esa carta una tensión entre quien va por su cuenta y

1 «Cabalgada», «porque aquello no puede equipararse a una campaña, dado que la resistencia fue mínima», considera Miralles. El «escudero», como se llamó a sí mismo, no tenía experiencia militar alguna, por lo que «casi podríamos asegurar que los afanes de meterse a conquistador responderían a una vocación tardía. Su currículo era tan pobre hasta ese momento, que de haber muerto por aquellos días, el mundo nunca se habría enterado de que una vez existió un hombre llamado Hernán Cortés» (2001: 60 y 64). Prien se pregunta también cómo se le encargó un mando si no tenía experiencia militar ni había destacado en expediciones o descubrimientos por el Caribe, según las fuentes disponibles hasta ahora. Tampoco se le puede imputar «que desde un principio se hubiera propuesto el objetivo de conquistar el Imperio Azteca, simplemente porque todavía no conocía con exactitud la geografía de la región y porque solo fue adquiriendo conocimientos más concretos sobre la existencia de ese imperio a medida que avanzaba la expedición» (1996: 19 y 20).

2 «Velázquez no estaba autorizado para poblar y conquistar nuevos territorios, sino solo para descubrir y comerciar [...]. Irónicamente, la falta de experiencia militar de Cortés pudo haber sido un factor importante en su elección [...]», aunque Bernal Díaz asegura que reclutó a soldados con la intención contraria: conquistar y poblar (Delgado Gómez, 1993: 16). 
riesgo hacia lo desconocido, o quien se asume el «designado» que podría acabar inmortalizado por sus proezas. De la Fuente recoge y comparte la misma opinión de José Antonio Maravall, expuesta en 1960, quien sugirió esa ambigüedad: «efectivamente, es un hombre entre dos mundos o épocas» (Fuente, 1999: 30) $)^{3}$.

En esta entrega, la intención es aportar algo más sobre esa mentalidad cortesiana, a partir de la escritura de la Segunda relación, en donde lo observamos fluctuante entre aquel que todo atribuye a Dios o bien, elabora pensamientos y actúa de acuerdo con su conciencia. Para ello será indispensable seguir de cerca dos corrientes cristiano-historiográficas, no necesariamente afines, que se intersectan en su misiva y que bien podrían estar presentes, en general, en el pensamiento del primer cuarto del XVI: la agustiniana-orosiana y la tomista. Trataremos de detectar cómo se crispan ambas historiografías, y la manera como el hombre-Cortés es fiel reflejo, a su vez, de la secular disputa teológica que ha habido entre los planes de Dios y/o de los hombres. Veremos cómo, a medio camino entre una y otra, Cortés se aprovecha de ambas, tal vez de modo involuntario, para elaborar una carta que, pese a sus propias incertidumbres, echa mano de un caudal retórico muy persuasivo: su propósito es convencer el apremio que autorizaría las guerras de conquista, pues nadie más habrá para encabezarlo en una hora crucial, cuando puede acontecer la victoria final. En particular, según se desprende de la Segunda relación, es a partir de sus triunfos en Tlaxcala (a principios de septiembre de 1519) cuando el capitán comienza a asumir que del Cielo viene su protección ante los peligros pues «Dios es sobre natura» (Cortés, 1993: 180)4. Aunque no queda esclarecido qué pulsión dominó (si la divina o la humana), cuando menos las utilizó con fines retóricos para persuadir a la Corona y lograr el propósito: legitimarse y recibir el permiso del rey para conquistar.

He elegido la Segunda relación ${ }^{5}$ por tres motivos: no se ha dudado de su autoría; al terminarla no había conquistado la Nueva España y fue divulgada

3 De la Fuente tiene como herederos de esa visión a Victor Frankl, con su trascendente artículo «Imperio particular e imperio universal en las cartas de relación de Hernán Cortés» (1963); también a Kathryn D. Kruger-Hickman, con su tesis doctoral Literaty Strategies of Persuasion in the "Cartas de relación» de Hernán Cortés (1987) y a José Luis Martínez, autor de una excelente biografía de Cortés, publicada en 1995.

4 « ¿Sabía Cortés adónde iba?», se preguntó Miralles. «No hay pruebas, pero un dato interesante [...], cuando desde la carabela tenga a la vista los templos de Yucatán no se interesará en ellos, sino que seguirá de largo, directamente hasta el arenal de Chalchicuecan [San Juan de Ulúa, Veracruz]. Como si de antemano tuviera fijado su punto de destino» (2001: 29).

5 Los originales de las cinco cartas están perdidos. Como hace notar Delgado Gómez, el Códice de Viena, que contiene todas, revela cómo pasó por la mano de varios escribas aunque «son seguramente transcripciones fidedignas de los originales». El Códice de Madrid no incluyó la Primera; a su vez, el manuscrito de la John Carter Brown Library contiene 
de inmediato en las prensas de Jacobo Cromberger (Sevilla, 8 de octubre de 1522). Fue escrita a lo largo de unos cuatro meses y su estilo se conserva más o menos homogéneo pero es variable el sentido, la mentalidad, cuando menos en los puntos que hemos anunciado ${ }^{6}$. Según todos los manuscritos, fue concluida en la villa Segura de la Frontera «de esta Nueva España», el 30 de octubre de 1520, luego de sofocar la revuelta de Pánfilo de Narváez, y ya habiéndose aliado con otros indios para acometerla sobre el reinado mexicano ${ }^{7}$. Para entonces, había pasado la Noche Triste (término perpetuado por Gómara), Moctezuma Xocoyotzin estaba muerto (29 de junio de 1520) y se habían sumado varias provincias al contingente español.

\section{La Providencia Divina, la providencia humana, el Libre albedrío}

El concepto «Providencia», luego convertido en «Providencia Divina»o «Divina Providencia» (en adelante, $D P$ ), no es de origen cristiano. Para Platón, en Timeo — al que seguirán Agustín, Orosio y Boecio, entre otros-, la naturaleza del cosmos va en contra de quienes aseguran tener "sus propios métra» (medida). Por el contrario, quien decide las medidas es un demiurgo, un hacedor de obras. Las tres causas o aitíai (nô̂s, technê y theò) «son en verdad una: un dios dotado de razón (nô̂s), que domina una technê, es quien introduce el orden en la naturaleza y hace, así, surgir el cosmos» (Escobar Moncada, 2003: 87).

Como palabra explícita, tampoco aparece en la Biblia aunque se pueda colegir, como en Platón, un tipo de funcionamiento providencial; es decir: hay acontecimientos que vienen de lo alto (en el pasado, el presente o el futuro) y en ellos no interviene la voluntad humana; son designios. Lo que sí se puede hallar, siguiendo a Christoph Strosetzki, es la doble expresión «señal y milagro»

una copia manuscrita de la Quinta, probablemente de mediados del XVI. Dicho sea de paso, el Códice de Viena deambuló hasta llegar a manos de Porfirio Díaz quien lo devolvió a la capital de Austria en 1911 (Delgado Gómez, 1993: 68, 70, 71, 73 y 66). Hasta 1889, en Sevilla, las cinco relaciones se publicaron bajo el título Copias de documentos existentes en el Archivo de Indias y en su palacio de Castilleja de la Cuesta sobre la conquista de Méjico.

${ }^{6}$ Se han detectado dos sitios distintos, cuando menos, donde escribió o reescribió: Tizatlán (hoy, en Tlaxcala) y Segura de la Frontera. Tizatlán no es mencionada explícitamente por el conquistador, pero sí por Bernal Díaz del Castillo, quien pone como fecha de esa vuelta el 23 de septiembre de 1520 . No se puede saber con precisión cuándo comenzó a redactar, pero debió ser después de la Noche Triste (30 de junio de 1520) pues refiere que perdió «todas las escrituras y abtos». En efecto, al huir aquella vez, perdió documentos, apuntes y quizá libros.

7 Ángel Delgado persuade que el editor Jacobo Cromberger debió tener acceso a una carta escrita por Cortés en 1521 y que llegó a España en marzo de 1522. Agrega que dicha carta nunca se ha hallado. 
o «señal y prodigio» en el Antiguo Testamento (18 menciones) y 33 milagros atribuidos a Jesús en los evangelios (1998: 240-253). Los milagros serán tema relevante, como se verá sobre todo con Tomás de Aquino, para la discusión teológica medieval sobre la Providencia.

Después de Cristo, quien llamó a la $D P$ por su nombre fue Séneca. Su Providencia (providentia o, como verbo latino, prouidere) es prever y proveer $\mathrm{u}$ ordenar unos medios para la obtención de un fin previamente querido. Por tanto, como sustantivo o verbo, es la parte de la Prudencia (la idea será retomada por Tomás de Aquino) que mira al porvenir; es decir, la obtención de un fin que aún no se logra $\mathrm{y}$, por tanto, la divinidad ordena y prescribe los medios que deben ser provistos para alcanzarlo en el futuro. En aras de ese designio, los dioses solventan bienes (beneficios) o males (adversidades). Por tanto, ser prudente es un ejercicio de la virtud (principio, también recuperado por santo Tomás) y, en todo caso, «no son males los que lo parecen; [...] son en primer lugar en favor de aquellos a quienes suceden, y después en utilidad de todos en general» (Séneca, 1789: 9).

Así, desde los estoicos, se concebía que no existe el azar sino un «orden divino» en donde Dios y el mundo están sometidos al «destino», con antelación dictado y plasmado en una ley infalible, el Hado (Martín Sánchez, 1991: 92) y, siguiendo a Séneca, la Providencia «es la consecuencia de la suprema sabiduría de Dios» (1789: 106) ${ }^{8}$, y la libertad humana no está negada, solo ceñida a ella.

Con Agustín de Hipona, la $D P$ «alcanza la categoría de ley histórica», mientras que su continuador, Orosio, la vierte al género de la historiografía cristiana (Agudo Romeo, 2000: 2) ${ }^{9}$. En La ciudad de Dios ${ }^{10}$, afirmó «con toda certeza», que la $D P$ es la que «establece los reinos humanos», jamás los astros $\mathrm{y}$, por tanto, no existe el destino sino la «libre voluntad». La palabra destino [fatum], tal como se suele usar, —es decir, la posición de los astros en el momento de la concepción del nacimiento de alguien- «es una expresión sin contenido que de nada sirve» (Agustín, 1988: 314). Sin embargo, puesto que

${ }^{8}$ Antes que él, en los fragmentos que se conocen de Sobre el destino, Cicerón negaba por igual que existiese el azar, aunque sí coincidencias azarosas en los hechos del mundo. Aceptó las predicciones pero objetando que predeterminaran el futuro. «No tienen por qué existir también causas naturales que antecedan a nuestra voluntad o deseo, pues, si la realidad fuera así, no quedaría nada a nuestro arbitrio» (Cicerón, 1999: 298-299).

${ }_{9}$ El género providencialista era en tres formas: la $D P$ es la organizadora de la historia; los milagros son el medio para interpretar los hechos históricos; y Dios actúa como juez de la historia.

${ }^{10}$ Fue terminada entre 426-427. Según Saranyana, las motivaciones del santo eran responder, teológica y filosóficamente, a la caída de Roma. Fue una obra de mucha consulta «para la justificación de la doctrina política medieval de matriz teológica» y hasta el fin del Medioevo y el Renacimiento. Ciudad de Dios es un ejemplo de «teología de la historia» (Saranyana, 2010: 644). 
es Dios el más alto poder y creador de todo, no hay nada que no ocurra dentro «de las leyes de su providencia» (1988: 322), concepción prestada de Platón (la métra es de Dios), de modo que la Civitate Dei no es otra que la ciudad eterna, donde reina el bien.

El Dios agustiniano se encarga personalmente de atribuir reinos e imperios, acorde con su plan y su gobierno, determinismo hasta cierto punto poco claro, a la luz de su ferviente defensa del libre albedrío humano, que divulgó desde entonces, y que dio inicio a no superficiales polémicas en el cristianismo, como la de las iglesias reformadas y durante la Contrarreforma, y aun, en nuestros días.

Para Contreras Peláez, la Providencia agustiniana va de la mano con la idea de «progreso», introducida mucho antes que los ilustrados, solo que incrustado en un tiempo lineal (no circular) irreversible e irrecuperable, en donde «a todos los pueblos les corresponde algún papel» pues hay una unidad humana. En síntesis, una especie de teología de la historia, aunque la discusión de si más bien se trata de una filosofía de la historia o un método historiográfico, sigue verificándose (Contreras Peláez, 2003: 246, 248 y 250).

Quien profundizó esta idea de tiempo lineal para construir la «ciudad de Dios» fue Paulo Orosio. Historia contra paganos (escrita alrededor de 415417), por cierto, tuvo una difusión considerable en España durante el Medioevo y en los inicios del Humanismo ${ }^{11}$. El discípulo de Agustín informaba en el preámbulo que, con ella, cumplía el encargo de su maestro ${ }^{12}$ para exponer una especie de «metodología de la historia», la cual sirvió, así en otras épocas, en las cortes de los Reyes Católicos como modelo de imitatio en sus cronistas, según Lafaye, citado líneas arriba (cfr. Tate, 1994: 17-28).

Orosio tampoco dudaba de que Dios no solo está presente en la historia sino que la dirige. Tras ofrecer un recorrido breve por los 5.618 años de la historia de Roma, concluía que todo lo que sobrevino a los grandes imperios antes de Cristo (Babilonia, Macedonia, Cartago y Roma) fue su condenación, decidida desde lo alto. Así, guerras, catástrofes, hambrunas, muertes y enfermedades, incluso, tras la caída de Roma. Al morir el redentor, las tragedias continuaron con la persecución de fieles pero, a la vez, la historia comenzó a llenarse de hechos providenciales; hubo ocasión para el milagro del convertido, del cristiano piadoso y valiente ${ }^{13}$.

${ }^{11}$ Se han hallado más de tres centenares manuscritos y 28 incunables. La primera edición impresa fue en 1471 (Bodelón, 1997: 63).

12 Orosio, Paulo (2010). El libro séptimo de las historias contra los pagano. Marta Gesino (trad. y notas). Disponible en: $<$ http://www.filo.uba.ar/contenidos/investigacion/institutos/historiaantiguaymedieval/Orosio_Libro_VI.pdf> [ref. de 16/05/2014], p. 50.

13 Teodosio, por ejemplo, —último emperador de Roma, cristianizado-, según habían contado Eusebio, Rufino y Agustín, se hallaba lidiando contra los usurpadores de su poder encabezados por Eugenio (año 394), cuando, ya casi perdido, se retiró a los Alpes a orar y 
En la apología de Orosio, como en La ciudad de Dios, el Omnipotente cristiano decide quién triunfa o pierde en una batalla; es un juez que verifica el acontecer humano y premia y castiga a sus fieles o a los que no lo son. Unas cuantas frases que ejemplifican lo anterior: «un solo Dios es árbitro de los siglos, de los reinos y de todos los lugares» ${ }^{14}$; Jesús, su Hijo, «anunció su Divina Providencia y fortaleció a los creyentes con su amonestación y confundió a los incrédulos con su predicción» ${ }^{15}$, basándose en Mateo 24, 6-9. ¿Y el libre arbitrio del hombre?

Boecio pretendió reconciliar el que ya era un conflicto teológico: si Dios tiene su albedrío y gobierna al mundo, ¿el hombre es solo un ejecutor de ese plan y no tiene potestad en la historia pues no ejerce su propia voluntad? $\mathrm{Su}$ obra De la consolación, muy leída en el XVI ${ }^{16}$, dejaba en claro, según Motto (2004: 84), que «Dios, en su absoluta simplicidad, rige todo a través de su Providencia. A esta, aplicada a cada uno de los múltiples objetos concretos, se la llama Destino». Boecio (m. hacia 524) sí creía en el azar, y coincidía con Agustín y Orosio en que el universo está gobernado por la $D P$ «con el timón de la bondad», aunque repitió que Dios premia a los buenos y castiga a los malos (también lo contrario, si el propósito es aleccionar). Pero este azar que viene de lo alto no anula, en ningún momento, la libertad humana: lo bueno y lo malo que acontece al hombre es por el parecer de Dios, para quien todo tiene sentido aunque no para el mortal. En De la consolación:

Fate and providence, God's «providentia» and «praevidentia», four levels of understanding, two kinds of necessity (simple/absolute and conditional), eternity and sempiternity. [...] God's infallible mode of knowing things is compatible with their contingent outcome, even though this seems to be impossible from the humble, human point of view (Nauta, 2009: 256).

Esta ambigüedad tampoco se resolvió con Boecio. Tomás de Aquino, en la misma línea que sus predecesores, ofreció como respuesta que si bien Dios «se encuentra presente y activo en todo lo que sucede y existe», cede a sus criaturas como segundas causas las verdaderas acciones y comparte con ellas a la

ayunar. Al día siguiente, ocurrió la extrañeza de que las flechas se devolviesen contra los subvertidos con ayuda del viento. De este modo, cuenta Orosio, «el cielo decidió entre los dos adversarios: uno, que sin ayuda de los hombres, solo puso humildemente su esperanza en Dios; el otro, que presumió con suma arrogancia de sus fuerzas y confió en los ídolos» (Orosio, Paulo (2010)..., véase supra la cita completa en nota 12, p. 41).

${ }_{14}$ Orosio, Paulo (2010)..., véase supra la cita completa en nota 12, p. 6.

15 Orosio, Paulo (2010)..., véase supra la cita completa en nota 12, p. 8.

16 «Its popularity was inmense, in fact, almost unparalleled. It was translated into different vernacular languages from an early time onwards, which ensured an unusually wide readership in which every stratum of society is represented: kings and Queens, the nobility, monks, clerics, university teachers, school masters and lay men and women» (Nauta, 2009: 255). 
vez el honor de la causalidad (Strosetzki, 1998: 241). Siendo Dios el primer motor no movible, «gobierna y rige con su providencia cuanto se mueve hacia el fin», acción que «no excluye [...] ni el defecto, ni el mal», que es de las segundas causas; esto es, no pertenecen a Dios (Aquino, 1998: 79). La DP «es la causa de todo bien» (1998: 84) ${ }^{17}$, por tanto, el albedrío de Dios no anula el humano; de ser así, desaparecería la virtud, la justicia, el consejo (1998: 87$88)^{18}$. En Suma Teológica lo explica aún mejor, mediante la separación de la Providencia Divina de la Humana. La primera, es la forma como Dios tutela al mundo mientras que, la segunda, es el gobierno de los hombres; en ambos casos, se trata de actos destinados a cumplir un fin (el Bien), como con Cicerón y Boecio. Dicho de otro modo: con la Providencia tomista se asume que hay un Dios que «provee» a un fiel que tiene necesidades individuales y que sabe tomar decisiones en orden a su salvación, para generar, junto con los otros, el perfecto gobierno de lo creado.

Puede suceder que ocurran cosas fuera del orden de la naturaleza, acepta Tomás, pero en modo alguno se debe entender que la obra en sí misma es contra la naturaleza sino que se trata de un milagro que, siguiendo a Cayuela, es aquello «que admiramos cuando viendo el efecto, ignoramos la causa» (2008: 91); hay grado y orden en ellos (es diferente detener el sol que curar a un ciego, ejemplifica). Como con Agustín, Dios sabe lo que hace, es inmutable $\mathrm{y}$, asimismo, premia o castiga la bondad o malicia de las acciones.

Lo que de esta obra quiero destacar, además de que el hombre resuelve en orden a la $D P$ es que, para Tomás, a diferencia de sus predecesores, la Providencia pertenece al futuro, «que todavía no es, pero que puede ser y que se intenta realizar» (Sellés, 1999: 36) ${ }^{19}$. Veamos: en el Tratado de la Prudencia (cuestiones de la 47 a la 56, II-IIæ pars de la Suma Teológica), la DP es parte de la Prudencia, la principal de las virtudes ${ }^{20}$. Esta, mitad razón y mitad apetito, es intelectual pero de índole moral; por tanto, media entre las virtudes

17 De igual modo que Boecio, trata de resolver la cuestión de que, si Dios es todo lo bueno, qué pasa con la libertad y con el mal que sufre el justo. Responde: «las acciones malas, en cuanto deficientes, no proceden de Dios, sino de sus causas próximas, que fallan» (Aquino, 1998: 85).

${ }^{18}$ El gobierno de Dios tomista es ejercido mediante la Ley (ley divina, traducida en ley natural) y la Gracia; el hombre es racional y libre pero «conducido y gobernado por Dios de manera razonable y respetando siempre la libre determinación de su voluntad» (Cayuela, 2008: 97).

19 Todavía Kant, en el siglo XVIII, como Aquino, será partidario de que «en la historia hay un cierto plan inteligible, un proceso racional dirigido hacia alguna finalidad pese a que las apariencias nos muestran una historia desordenada, llena de sucesos inútiles, penosos, librados al azar y fuera del control humano» (Sanguineti, 1985: 200).

${ }^{20}$ «Es una virtud intelectual que capacita para aplicar rectamente la verdad a la vida moral $[\ldots][y]$ es madre y moderadora de las demás virtudes: sin la prudencia no existe la justicia, la fortaleza ni la templanza» (Trigo, 2002: 283). 
intelectuales y las morales (Cayuela, 2008: 287). La Prudencia se hace acompañar de otras ocho partes cuasi integrales o requisitos imprescindibles: memoria, razón, inteligencia, docilidad y sagacidad (son cognoscitivas); previsión o providencia, precaución y circunspección (preceptivas). La previsión, en la Suma de Teología, es «ordenar algo adecuado a un fin» (Aquino, 1990: 416).

Trigo realza que, conforme declinó el Medioevo, la importancia de la Prudencia comenzó a trasladarse del intelecto a la conciencia. Será sobre todo en el XVI y en el XVII cuando «alcance todo su vigor la polémica sobre los "sistemas de moralidad", gracias, en gran parte, al papel que se le atribuye a la conciencia, y a la necesidad de decidir qué corresponde a la ley y a la libertad cuando la conciencia es dudosa» (Trigo, 2002: 284) ${ }^{21}$.

En el Renacimiento, la $D P$ comenzó a imponerse sobre la Humana. Además, no era la Providencia querrá y, por ello, proveerá al estilo tomista, sino que la Providencia quiso y por ello proveyó. Se seguirán «confundiendo» los designios de Dios con los de la propia voluntad y la aparición de hechos milagrosos de carácter profético llevarán a la convicción de que, como desde el de Hipona, hay un plan de salvación en el que el hombre es un mero instrumento. Fatalismo contra libre albedrío de nuevo.

\section{PROVIDENCIALISMOS Y LIBERTAD EN EL SIGLO XV}

Los primeros conquistadores estaban absortos ante el «mundo nuevo» que tenían ante los ojos. ¿Cómo explicarlo? Quizá mirando al Cielo, resignándose a verlo como obra de Dios. Frost reflexionó al respecto que:

[...] Toda la historia transcurrida antes del nacimiento de Cristo, sea la judía o la gentil, es vista como una praeparatio evangelica, en tanto que toda la historia posterior - lo ocurrido después de la muerte redentora de Cristo- es el intervalo decisivo, el tiempo de la prueba, el momento de la separación entre el trigo y la cizaña, el tiempo de lucha entre la inclinación al pecado y la misericordia divina que solo terminará con el triunfo final de la fe [...]. Así, San Agustín afirmó que vivimos ya en la plenitud de los tiempos, en la última edad a la que pondría fin la parusía del Señor. La historia tiene en consecuencia un sentido: es una historia de la salvación. Y a esta concepción de la historia que, como hemos visto tiene más de teología que de filosofía de la historia, es a lo que se llama providencialismo (1996: 17).

${ }^{21}$ La Prudencia tomista puso de relieve la combinación de dos elementos indispensables: juicio recto y decisión de la voluntad. «La Prudencia [...] ha de estar de acuerdo con los juicios morales que formula la conciencia. La Prudencia sabe leer en la conciencia la rectitud moral de lo que juzga como bueno o como malo» (Fernández, 2003: 239). 
Es idea aceptada que, en la mentalidad de la época, dominaba la idea de que España podría ser la siguiente nación en fila para continuar el plan de un reino cristiano universal, exento de paganismo, herejías, ateísmo y cualquiera otra rémora. La pluma de muchos intelectuales estuvo al servicio de dicho propósito, como sostiene Lafaye:

Los cronistas de la corte de los Reyes Católicos trataban de interpretar cada acontecimiento cual si fuese signo providencial del favor de Dios otorgado a la pareja real de la monarquía bicéfala («tanto monta...»), y de presentar su política (dentro y fuera de España) como un combate por la fe cristiana, como una cruzada (1997: 50).

En las primeras décadas del XVI, incluso, se generalizó «la expresión "Monarquía católica" o "Monarquía universal española" [...] [porque] procedente de oriente y pasando a los griegos y a los romanos, llega por último, a los españoles» (Carmona Fernández, 1993: 14). Américo Castro, por su parte, opinó que el descubrimiento de América vino a ratificar «los anhelos y vaticinios imperialistas» de la península, proyectados, a su vez, por el:

[...] mesianismo hispano-judío, que se infiltra como importante ingrediente en el ánimo del pueblo hispánico. Los Reyes Católicos comenzaron a reinar en un ambiente denso de vaticinios y misteriosos signos, que los actos de aquellos monarcas parecían justificar ya desde el principio (1987: 22).

Tenemos, pues, que en este lapso que va de finales del XIV a principios del XV, «la literatura española hierve de problemas relativos a la Providencia, postrimerías y premeditación, libre albedrío y astrología» (Márquez Villanueva, 1997: 131 $)^{22}$. Se traducían clásicos y abundaban «iluminados, mesiánicos, imperialistas y erasmistas» (Castro y Castro, 1954: 37), en una época en la que se cocinaba la reforma luterana ${ }^{23}$. Precisamente, uno de los distingos de Martín Lutero con el catolicismo fue la creencia en la predestinación y la negación del

${ }_{22}$ Algunas obras de la época: el Tratado breve en las influencias del cielo, de Abraham Ben Samuel Zacut; el Tratado de Providencia contra Fortuna, de Diego de Valera; el Tratado del caso y la fortuna, de fray Lope de Barrientos; Diálogo sobre la predestinación y el libre albedrío, de Gonzalo Morante de la Ventura y Compendio de la fortuna y el Tratado de la predestinación, de Martín Alonso de Córdoba.

${ }^{23}$ Salvo la primera carta de Colón, de 1493, del 15 de febrero de 1493, y que gozó de una enorme difusión, no hallamos ningún testimonio contemporáneo en torno al descubrimiento o las guerras de Conquista, en donde los triunfos se atribuyan a la $D P$, explícitamente. Si acaso, en esa carta de Colón se lee la la expresión «Nuestro Redentor dio esta victoria a nuestros ilustrísimos reyes», que no deja de ser una muletilla discursiva. Pero esa victoria es por haber ganado la Isla Española, no por el descubrimiento de un nuevo continente. Como se sabe, murió en 1506, creyendo que había llegado, no a América sino a Cipango (Japón). 
libre albedrío, base de la polémica de auxiliis, protagonizada entre dominicos y jesuitas: véanse la Concordia del libre arbitrio con los dones de la gracia y con la presciencia, providencia, predestinación y reprobación divinas (1588), de Luis de Molina, o las Disputaciones metafísicas (1597), de Francisco Suárez; en particular, la Disputación XIX, sobre la causalidad divina y la libertad humana. El tema ya había sido tratado por Lorenzo de Valla con De libero arbitrio, discusión que continuó Erasmo con De libero arbitrio diatribe sive collatio (1524), la cual Lutero rebatió en una histórica polémica, con De servo arbitrio, publicada al año siguiente.

Tocante al tema propuesto, vamos a ver cómo en la Segunda relación de Cortés se pueden encontrar elementos del providencialismo agustiniano-orosiano y del tomista, mezclados y hasta confundidos: las victorias del pasado fueron dispuestas por Dios mientras que las victorias del futuro que se ven venir, serán ordenadas por Dios y él será su ejecutor como segunda causa. Permea el ya esbozado desconcierto entre qué dispone Dios y qué el hombre-Cortés en una empresa que, para cuando redacta, está aún sin consumar.

Los tránsitos cortesianos de uno a otro providencialismos no se registran de inmediato. Se hacen más presentes luego de las primeras victorias contra los culúas o mexicanos en donde, suponemos, hay una maduración, un trabajo de «conciencia» por parte de su autor quien tiende más hacia la historiografía agustiniana-orosiana. Veamos algunos ejemplos cronológicos que irán revelando el cambio en la participación providencial en la mente de Cortés ${ }^{24}$.

Fuera de unos cuantos encontronazos con indígenas que recibían a los españoles bien o mal, la primera vez que Cortés atribuye a lo alto algún acontecimiento del pasado, se verifica al narrar lo sucedido en Villa Rica de la Vera Cruz, mientras él marchaba de Cempoal con rumbo a México. Hacia los primeros días de septiembre de 1519, fue informado de la presencia de unos barcos al mando de Alonso Álvarez de Pineda, enviados por Francisco de

${ }^{24}$ No son ajenas, como para ningún otro cristiano del siglo XV (o de nuestros tiempos), muletillas del discurso que no necesariamente atribuyen a Dios algún suceso. Cortés las usa a menudo. Unos ejemplos: «Dios sabe cuánto trabajo la gente padesció de sed y de hambre...»; «con ayuda de Dios y de su gloriosa madre...»; «ayudándonos Nuestro Señor»; «Dios sabe cuánta alteración rescibí»; o «Dios sabe cuánto trabajo y peligro rescebí». Incluso, con toda intención, refiere que en Tenochtitlán había «muchas mesquitas», en clara referencia al mundo islámico (Cortés, 1993: 170, 275, 276, 277 y 281). Un biógrafo anónimo de Cortés (Vida de Hernán Cortés), cuyo texto se tiene hoy de manera fragmentada, se ufanaba de este modo: «Búrlense cuanto quieran los que piensan que las cosas humanas dependen del acaso; yo para mí tengo que de toda eternidad está señalado a cada uno por decreto inmudable el camino que debe correr» (García Icazbalceta, Joaquín [ed.] [1999]. «Vida de Hernán Cortés», en Colección de documentos para la historia de México. Disponible en: <http://www.cervantesvirtual.com/obra-visor/coleccion-de-documentos-para-la-historia-de-mexico-version-actualizada--0/html/21bcd5af-6c6c-4b27-a9a5-5edf8315e835_3.htm\#4> [ref. de 01/10/2014], s/n). 
Garay con intenciones de competir en el trabajo de conquistar. El jefe los mandó detener mientras Pineda escapó, escena no exenta de inconvenientes pero también de milagros que, según Tomás, recuérdese, son obras «fuera del orden de la naturaleza»: uno de los exploradores, el «maestre de la una nao», puso fuego a una escopeta con el propósito de matar a Juan de Escalante, alguacil mayor de Veracruz pero, al intentar disparar, «quiso Nuestro Señor que la mecha no tenía fuego» (Cortés, 1993: 167).

La segunda «acción providencial» acaeció en Tecoac a los pocos días, en donde fue asaltado por unos 15 indios otomíes y donde se le murieron dos caballos (a causa de las heridas fallecería, además, Pedro de Morón). En cuestión de horas, las fuerzas del rey Sintengal (Xicoténcatl el joven) arremetieron pero, esta vez, con «cient mill hombres» por la noche:

y peleamos con ellos y ellos con nosotros todo el día hasta una hora antes de puesto el sol que se retrajeron [...]. Y bien paresció que Dios fue el que por nosotros peleó, pues entre tanta multitud de gente y tan animosa y diestra en el pelear y con tantos géneros de armas para nos ofender salimos tan libres (Cortés, 1993: 177).

La tercera se presentó, en el mismo mes y año, cuando llegaron «más de ciento y cuarenta y nueve mill hombres» tlaxcaltecas al ataque. «Salimos a ellos y quiso Nuestro Señor en tal manera ayudarnos que en obra de cuatro horas habíamos fecho lugar para que en nuestro real no nos ofendiesen» (Cortés, 1993: 178). Nótese que fue en tiempo pasado. En esos días, ya «algo descansado», tomó un paseo nocturnal y «después de rondada la guarda de la prima», a una legua de su real, comenzó a ver señales y designios:

Se me cayeron cinco de los caballos y yeguas que llevaba que en ninguna manera los pude pasar adelante, e hícelos volver. Y aunque todos los de mi compañía decían que me tornase porque era mala señal todavía seguí mi camino, considerando que Dios es sobre natura (Cortés, 1993: 180) ${ }^{25}$.

Las anteriores citas revelan, en mi parecer, un uso retórico espontáneo de la ayuda de Dios. No se aprecia lo mismo a partir de mediados de septiembre de 1519 cuando, estando en Tlaxcala, se verifica una primera convicción personal en Cortés de que algo providencial está por ocurrir (providencialismo tomista para el futuro). Si «Dios es sobre natura» desde lo alto estarían, en su mentalidad, comenzando a revelarse señales que debe aquilatar y orientar en prescripción a un fin. Por lo anterior, en la cuarta mención ya estará en condi-

${ }^{25}$ Tapia, testigo de vista de este episodio, asienta que Cortés atajó las advertencias con esta sentencia: «¿Por qué miráis en agüeros? No dejaré la jornada, porque se me figura que de ella ha de seguir mucho bien esta noche, y el diablo por estorbar pone estos inconvenientes» (2008: 49). 
ciones de detectar a un Dios, ahora de vuelta al estilo agustiniano, el cual comienza soltar los primeros signos de un plan, aún no conocido a cabalidad.

Insisto en la importancia de tener presente que Cortés, cuando desembarcó el 14 de marzo de 1519 en Yucatán, no tendría la idea de estar acometiendo la conquista de un imperio aunque sí, concedemos, una vaga noción de lo que podría hallar. Sin embargo, para el 24 de abril ya se había reunido con los primeros enviados de Motezuma (Moctezuma). Por lo anterior, tiene lógica su insurrección ante Diego Velázquez: tras fundarse el primer cabildo en Veracruz, en julio de 1519, dimitió como capitán general del gobernador de Cuba y las «nuevas autoridades» lo nombraron «capitán general de la Nueva España», al mando de una expedición distinta que ahora obedecería al rey ${ }^{26}$. Con razón, Diego Velázquez no entendía cómo su «criado y amigo» al que pensó «cuerdo» y resultó tan codicioso y asesino, tomó camino hacia las islas de los Lucayos, «navegación no sabida ni usada, por muy escondido e peligroso viaje» ${ }^{27}$.

Entre marzo y abril de 1519, entonces, el Cortés sublevado busca razones y es lícito afirmar que las iba encontrando en el Cielo. De hecho, estaba obligado a tenerlas, cuando menos para sí mismo, pues estaría condenado si no tenía éxito en su empresa, en la que se movía en la ilegalidad ${ }^{28}$. Cuando más de cuatro mil tlaxcaltecas se rindieron, ofreciéndole paz y alianza, expresaba

${ }^{26}$ El derecho sobre las Indias Occidentales había sido dado a los Reyes Católicos por la bula del Papa Alejandro VI. En la instrucción recibida por Velázquez el 23 de octubre de 1518, se le había solicitado hablar de Roma así que, según Zavala, Cortés conocía muy bien el «derecho de guerra», la "causa justa» y la «recta intención» de orden escolástico, vigente en su época (1985: 15-35). A propósito, el oidor Vázquez de Ayllón, partícipe de la subversión de Narváez, logró llegar a Santo Domingo y allí redactó un informe al rey de fecha 30 de agosto de 1520. Miralles destaca que se verifica dos meses antes del envío de la Segunda de Cortés y que, en tal, el oidor narra que regresaron costeando hasta Ulúa (Vera Cruz) donde se cree que es «tierra firme» (2001: 207).

${ }^{27}$ Fechada el 17 de noviembre de 1519, y destinada al licenciado Figueroa, Velázquez pormenorizaba una "grande maldad y feo caso», ocurrido por una armada que envió a explorar, a cargo de «un Hernando Cortés». En vez de pacificar, «conformándose con mi instrucción, tuvo tanta fuerza con la codicia, como muchas veces es raíz de los males [...] por robarlas alborotó y mató» a muchos indios (Velázquez, Diego [1999]). «Carta que Diego Velázquez escribió al licenciado Figueroa, para que hiciese relación a sus majestades de lo que le había hecho Fernando Cortés», en Joaquín García Icazbalceta [ed.], Colección de documentos para la historia de México. Disponible en: <http://www.cervantesvirtual.com/ obra-visor/coleccion-de-documentos-para-la-historia-de-mexico-version-actualizada--0/html/ 21bcd5af-6c6c-4b27-a9a5-5edf8315e835_6.htm\#31 5.htm\#31> [ref. de 01/10/2014], s/n.

${ }_{28}$ En la óptica de Prien, esta misma circunstancia lo obligó a elaborar «una construcción legal según la cual pudiera presentarse como un celoso servidor de los verdaderos intereses de la Corona de Castilla» que ya había ensayado desde la Primera (1996: 20). El elemento religioso sería incorporado más adelante, cuando estaba en Tabasco (1996: 24), aspecto que iba a explotar en las siguientes cartas. Se trataría de la soberanía religiosa de la Iglesia romana, de la soberanía política de la corona y de asegurar la evangelización (1996: 29). 
con cierta sinceridad que se manifestaba «la vitoria que Dios nos había querido dar» (Cortés, 1993: 181) pues, de verdad sorprendería a más de uno, la masiva adhesión de militantes y la «obligación» que tendría de que «estas gentes fuesen introdocidas e instrutas en nuestra muy santa fee católica y conmutada la devoción, fee y esperanza que en estos sus ídolos tienen en la divina potencia de Dios» ${ }^{29}$. Y como él mismo se convencía, intentaba persuadir a los soldados de continuar porque, a la manera de Orosio, había que exaltar la fe. Escribió que a los soldados arengaba con el argumento de:

[...] que estábamos en disposición de ganar para Vuestra Majestad los mayores reinos y señoríos que había en el mundo que demás de facer lo que a cristianos éramos obligados en puñar contra los enemigos de nuestra fee, y por ello en el otro mundo ganábamos la gloria y en este consiguíamos el mayor prez y honra que hasta nuestros tiempos ninguna generación ganó; y que mirasen que teníamos a Dios de nuestra parte y que a él ninguna cosa es imposible, y que lo viesen por las vitorias que habíamos habido, donde tanta gente de los enemigos eran muertos y de los nuestros ningunos (Cortés, 1993: 182).

Como percibió que funcionaba, especulo que pudo entonces apropiarse de ese discurso conveniente y convenenciero para dirigirse al rey, a través de una carta que tuvo tiempo para elaborar y reelaborar. De la Fuente advierte que, a la hora de leer las cuatro misivas de Cortés, se tiene que considerar que «cada palabra, por tanto, está perfectamente medida para que surta su efecto en la mente y en los propósitos del monarca» (1999: 32). Las cartas son un arma «de la que dispone para legalizar y confirmar sus acciones» (Fuente, 1999: 37). En lo personal, no puedo afirmar que él mismo no creyera su papel mesiánico como tampoco lo contrario. Quizá, hablar y escribir así era la única opción que le quedaba.

Tan fue efectivo el discurso a la tropa que esta siguió a su lado camino hacia Tenochtitlán. Díaz del Castillo da fe de la emoción que provocaban las proclamas del militar.

Para su primer encuentro con Moctezuma, el 8 de noviembre de 1519, Cortés no tenía dudas de ser el elegido, por voluntad de Dios o por sus arrestos, y que los monarcas debían verlo tal cual (providencialismo para el futuro), pues

29 Ángel Delgado hace notar que López de Gómara, sobre este pasaje, incluso señaló que el apóstol Santiago peleó en su caballo blanco junto a los españoles. Bernal Díaz apuntó que acaso, «yo, como pecador, no fuese digno de verlo», aunque había «sobre cuatrocientos soldados [...] y hasta que leí su corónica nunca entre conquistadores que allí se hallaron tal les oí» (Díaz del Castillo, 1977: 115-116). Hernández LeFranc sigue el recorrido del patrono de España hasta América en varias crónicas. Por ejemplo, apareció en Iximché, donde se habría de edificar la antigua ciudad de Guatemala, según Francisco Fuentes y Guzmán, el 25 de julio de 1524. También, en Jauja, Perú, a las tropas de Pizarro en 1533 en la obra de Antonio de Herrera (2006: 67 y 73). 
iba a necesitar financiación pero, sobre todo, legalidad, luego de las acusaciones de Velázquez ${ }^{30}$.

Aunque latente ese dilema sobre su voluntad, con o contra la de Dios, también Cortés aprovechaba la ocasión para manipular. Claro ejemplo de un uso interesado de la retórica es su versión de la cita con el tlatoani azteca, uno de los pasajes que más se ha discutido entre los historiadores. Moctezuma le habría contado que su pueblo venía «partes muy estrañas» y que esperaba el día que viniesen los representantes de un rey que vive «hacia a do sale el sol» para ser sojuzgados: «Vuestra Majestad era a quien ellos esperaban», escribió a Carlos I de España (Cortés, 1993: 212) ${ }^{31}$.

Aquí la teología historiográfica orosiana, hecha invención retórica, cobra todo vigor: cuando redacta el pasaje, explota su condición de designado divino, en una difícil tirantez entre lo que podría pensar de sí mismo (si lo era o no) y lo que el destinatario debía pensar de los hechos narrados. Incluso, transcribe el discurso que ofreció a los mexicanos, luego de colocar una imagen de la Virgen y de otros santos en el Templo Mayor, cosa que él suponía estaba destinado a funcionar: hay nuevas tierras ofrecidas por Dios para evangelizar. El Dios universalista, contra los «paganos», al modo de Orosio, aparece:

[...] y que habían de saber que había un solo Dios universal señor de todos, el cual había criado el cielo y la tierra y todas las cosas que hizo a ellos y a nosotros, y que este era sin principio e inmortal y que a él le habían de adorar y creer, y no a otra criatura ni cosa alguna (Cortés, 1993: 239).

Sin embargo, el Dios providencial que define todo desde el principio de los tiempos, a la manera agustiniana o tomista, desaparece de súbito, por varios meses. Es inevitable sospechar si todo el tema de predeterminismo, expuesto antes de mayo de 1520, era un sentimiento que en realidad embargaba a Cortés, o más bien pretendía compaginar sus anhelos con los de sus monarcas: persuadir a Carlos I de España de que su reino era el elegido desde lo alto para seguir construyendo la «Ciudad de Dios», como vaticinaban en aquellos años. La suspensión de la moción divina de su discurso se debió a hechos mucho más mundanos: «entrante el mes de mayo» de 1520, tuvo reseña de una nueva persecución mandada por el gobernador de Cuba, a través de Pánfilo de Nar-

30 Para el 14 del mismo mes, Moctezuma ya ha sido apresado. La narración cortesiana sobre este episodio «puede interpretarse como una muestra más de la forma en que el autor-protagonista se plasma en su escritura como instrumento de la Corona española» (Aracil Varón, 2008: 157).

31 Se ha señalado si fue que el rey azteca tal contó, si más bien lo parafraseó Cortés o, de plano, lo inventó o acaso alguien más. Más adelante, pondrá en boca de Moctezuma otro discurso en donde el rey supuestamente admite el vasallaje a España por mandato de los dioses, que se sigue discutiendo pues se supone, según Bernal, que el único presente era el paje Orteguilla (Véase nota 249 de Delgado Gómez, 1993: 228). 
váez, con el fin de relevarlo de la capitanía general y si fuese necesario, asesinarlo $^{32}$. Delgado Gómez considera lógico que, para contrarrestar las graves acusaciones de Velázquez:

contra su persona [...] Cortés trate de convencer al emperador que claramente es Dios quien guía a él y a sus conquistadores - a quienes muy significativamente insiste en llamar los suyos, es decir los de Dios-- desde el momento mismo en que la flota llega a la costa de Yucatán (1993: 23).

Sin embargo, ¿cómo resolvemos el tema del tiempo, es decir, que aún no había conquista? ¿De verdad Cortés solo emplea la persuasión para legitimarse en una guerra que no había ganado aún? ¿No está en un dilema, cuando menos teológico, de atribuir a Dios una fuerza que no se explica y, por otra, de ser víctima de sus propios empeños? Otra vez, la pugna entre la Providencia (del pasado o del futuro), y la libertad humana.

Para enfrentar el nuevo acecho, ya no hay duda de que Cortés hace oficio de su Providencia Humana, a la manera tomista. Primero, se jacta de haber sabido a tiempo las pretensiones de Velázquez y, segundo, de haber maniobrado con diligencia para conjurar la «traición». Pero, como era prudente no exaltar ante la corte su albedrío sino su rol ejecutor de un gobierno celestial, le reveló el plan «Dios, quien en semejantes casos remedia» (Cortés, 1993: 260). En esta parte es clara la intención persuasiva en su escritura: el rey debía corroborar que él no era el traidor sino Velázquez y Narváez, llenos de «mala intención y dañada voluntad»:

Dios lo había fecho y proveído. Porque certifico a Vuestra Majestad que si Dios mistiriosamente esto no proveyera y la vitoria fuera del dicho Narváez fuera el mayor daño que de mucho tiempo acá en españoles tantos por tantos se ha hecho (Cortés, 1993: 265).

Podría leerse de este modo: si él no encabezaba la guerra contra los culúas, sobrevendría la hecatombe del reino. A mirar que en estas palabras de Cortés no hay sutileza; parece como si afirmase, jactancioso, que da fe de la voluntad de Dios y que, desde el Cielo, su causa está determinada a triunfar.

Obsérvense pues, las vacilaciones sobre su providencialismo: ¿es para los hechos del futuro o del pasado? Los hechos inexplicables que le han ocurrido, ¿son milagros, azares o claves para entender el «designio» divino? O bien, ¿en todo ello lo único que ha resultado sorprendente es su capacidad de tomar

32 A ello dedica una buena parte de la carta (Cortés, 1993: 251-265), hasta que Narváez cae preso el 27 de mayo de 1520; fue trasladado a la prisión en Veracruz y allí pasó dos años más. 
decisiones? ${ }^{33}$. Acaso, no le queda más que escribir de forma convincente, sin dejar de darse a sí mismo explicaciones a sucesos que jamás imaginó estar atestiguando.

Sigamos. Pasado el trago amargo, Cortés retornó a Tenochtitlán el 24 de junio de 1520. A los pocos días se verificó una masacre en el Templo Mayor, evento silenciado ${ }^{34}$ en la Segunda, donde habrían caído hasta 600 indios (Miralles, 2001: 212) y donde fue herido de muerte Moctezuma. En esos eventos, estuvo a punto de fallecer él también: comenzó a trepar una torre (teocalli), «manco de la mano izquierda de una herida», al tiempo que los adversarios atacaron con flechas y varas, y apenas si derrocaron a «tres o cuatro españoles, con ayuda de Dios y de su gloriosa madre» hasta que por fin pudo colocar una imagen de la Virgen en lo más alto, mientras arriba siguieron «peleando» por más de tres horas hasta que murieron todos los indios y ninguno escapó:

Y crea Vuestra Sacra Majestad que fue tanto ganalles esta torre que si Dios no les quebrara las alas bastaban veinte dellos para resistir la subida a mill hombres, comoquiera que pelearon muy valientemente hasta que murieron (Cortés, 1993: 275).

Al monarca, la antedicha escena podría haberle evocado la historia de Teodosio, contada por Orosio: después de encomendarse a Dios durante la víspera, salió a pelear al día siguiente y vio cómo, de manera milagrosa, las flechas de los contrincantes, encabezados por Eugenio, se volvían contra ellos y les mataban. Ahí está el milagro que ofrece Cortés. Como no hay victoria definitiva, podría tenérsele por sincero pues los españoles estaban a punto de ser vencidos. El 30 de junio de 1520 le había enseñado que los mexicanos estaban dispuestos a defenderse de un intruso y a no ceder sus dominios; pero, también, le habría hecho caer en la cuenta de que, siendo miles los muertos, era obligada una especie de tregua temporal. Aquella Noche Triste se encaminó por Tacuba, adonde lo siguieron para atacarlo aún más: «Dios sabe el trabajo y fatiga que allí se rescibió, porque ya no había caballo de veinte y cuatro que nos habían quedado que pudiese correr ni caballero que pudiese alzar el brazo ni peón sano que pudiese menearse» (Cortés, 1993: 281).

Como pudo, huyó de nuevo en dilema: darse por vencido o rearmarse y volverlo a intentar. Recuérdese, otra vez, que Cortés terminó la misiva sin haberse consumado la caída de la ciudad, así que pueda ser esta etapa en don-

33 Vidaurre, al realizar un estudio semiótico de la Segunda, refiere que el comportamiento del remitente, característico de su tiempo, «se hace evidente que el lenguaje le sirve como arma de manipulación, a la vez que como instrumento de conocimiento» (1996: 39).

34 Aracil Varón ha analizado la manera como Cortés supo construir su «yo protagonista» a través del sujeto gramatical. La elipsis, por ejemplo, le permitió omitir información que no redujera su protagonismo como en el de este momento o de la cita que sigue, en donde debe mostrarse valeroso a cabalidad aunque esté manco de la mano izquierda (2009: 68). 
de su providencialismo podría tenerse por sincero otra vez. No era para menos la decepción: hambre, enfermedades, falta de agua, muertos por doquier. Estimulaba a sus seguidores a confiar en él, pues era el predestinado y, si no, cuando menos que se lo creyeran. Por ello, evocaba que cada hecho en las pasadas batallas de Tenochtitlán, entre mayo y junio de 1520, llevaban el signo celestial y exornaba: si no lo seguían a él, ¿se incumpliría la orden divina? Resultará interminable reproducir todas las pinceladas que ofrece su narración, a partir de este momento, sobre el papel que se adjudica en la historia de salvación, pero tomaré las más significativas.

Los soldados debían «seguir la victoria que Dios nos daba»; «y Dios nos dio ansimesmo tan buena dicha y vitoria...»; «y quiso Nuestro Señor que ya que la noche venía mostrarnos una torre y buen aposento [...] donde ansimesmo nos hecimos fuertes»; «no teníamos después de Dios otra seguridad sino la de los caballos» (Cortés, 1993: 276, 277, 283 y 285).

Concediendo que fuesen muletillas cristianas, Cortés, de otro modo también, quiere convencerse y convencer de que, si ya llegaron hasta tan alto, lo que se requería es tenacidad pues Dios ya está presente, activo y contribuyendo a la consumación del laurel sobre Tenochtitlán. Por eso, él convidaba a sus huestes a comprender el momento histórico que les tocaba protagonizar y seguir guerreando. Cuando percibía el «poco ánimo» generalizado, se acordaba de que:

[...] siempre a los osados ayuda la fortuna $a^{35}$ y que éramos cristianos y confiando en la grandísima bondad y misericordia de Dios, que no permitiría que del todo pereciésemos y se perdiese tanta y tan noble tierra como para Vuestra Majestad estaba pacífica y en punto de se pacificar ni se dejase de hacer tan grand servicio como se hacía en continuar la guerra (Cortés, 1993: 290).

¿Azar o providencia? ¿Albedrío divino o humano? ¿Destino o predestinación? ¿Providencia Divina o Humana? De nuevo la tensión que Cortés resolvió, por fin, tomando decisiones por su cuenta y riesgo: se rehusó a seguir los consejos de quienes le pedían que, dadas las condiciones deplorables de su ejército, «y temiendo los por venir», marchara a Veracruz. Como se advierte con claridad enseguida, anunció que la ofensiva seguiría:

[...] acordé y me determiné de por ninguna manera bajar los puertos hacia la mar; antes pospuestos todo trabajo y peligros que se nos podiesen ofrescer, les dije que yo no había de desamparar esta tierra porque en ello me parescía que demás de ser vergonzoso a mi persona y a todos muy peligroso a Vuestra Majestad hacíamos

\footnotetext{
${ }^{35}$ Nótese que es la fortuna, el azar, el que contribuye. Para ampliar sobre el debate de fortuna y providencia en el siglo XV, se puede consultar Mendoza Negrillo (1973). Entre los preceptistas castellanos del XV llegó a igualarse la Fortuna con la $D P$, o la consideraron independiente de ella o la siguieron llamando «diosa».
} 
muy grand traición, y que antes me determinaba de por todas las partes que pudiese volver contra los enemigos y ofenderlos por cuantas vías a mi fuese posible (Cortés, 1993: 290-291).

No se pierda la aparente nimiedad discursiva: ahora no es Dios quien le pide reanudar la intentona de conquista sino que él lo ha decidido por honor, para sacudirse la vergüenza, pretendiendo convencer de que esa lucha permitirá prestar un gran servicio a Dios y al Papa. Aquí está la Providencia Humana: el guerrero volverá a la batalla hasta la victoria.

Entonces, el capitán desestimó volver a Veracruz y paró en Segura de la Frontera (hoy, estado de Puebla), en la ya nombrada «Nueva España» para reorganizar su ejército. No hay victoria aún pero se avizora o se presiente, qué más da. Y así termina la misiva: «por manera que fasta agora he tenido en qué entender en esta guerra, y aún todavía no es acabada porque me quedan algunas villas y poblaciones de pacificar» (Cortés, 1993: 292).

La Segunda fue despachada a España en las manos de Alonso de Mendoza hasta el 5 de marzo de 1521. Si se agrega la dilación que implicaba cruzar el Mar Océano, transcurrieron otros cuatro meses más pues, entretanto, Cortés y su ejército rindieron a la ciudad el 13 de agosto de 1521. Para cuando llegó al rey, este bien pudo haber noticias previas de la victoria. La carta fue publicada por Cromberger y, de acuerdo con González de Barcia, el editor pudo haber tenido acceso a una carta previa, de agosto de 1521 y llegada en marzo de 1522, la cual «nunca se ha hallado», según Delgado Gómez (1993: 309). Lo anterior pues el texto cortesiano que hoy conocemos, tiene una adenda crucial:

[Después désta, en el mes de marzo primero que pasó vinieron nuevas de la dicha Nueva España, cómo los españoles habían tomado por fuerza la grande ciudad de Temixtitán, en la cual murieron más indios que en Jerusalén judíos en la destrucción que hizo Vespasiano (...)] (Delgado Gómez, 1993: 309) ${ }^{36}$.

Vamos a sacar, ahora, algunas conclusiones.

Cortés, sin duda, compartía con su época el espíritu que mezclaba dos corrientes tradicionales para la cristiandad: el providencialismo agustiniano-orosiano sobre el pasado y el tomista, sobre el futuro. Los usó indistintamente para explicarse a sí mismo, a sus soldados y luego a sus destinatarios, los hechos que le había tocado atestiguar y los que avizoraba iban a acontecer. Junto con ese espíritu, Cortés también reflejó el secular dilema entre los designios de Dios y las decisiones humanas. Si bien no debe descartarse que fuese sincero en dos o tres ocasiones, sobre su papel de iluminado para otorgar a España la estafeta en la construcción de la «Ciudad de Dios», tampoco puede

36 La Tercera relación, por cierto, estará fechada en Cuyoacan (Coyoacán), a 15 de mayo de 1522 . 
afirmarse que toda la carta solo echase mano de argucias retóricas. El soporte de lo anterior es la fecha de conclusión: 30 de octubre de 1520 .

No obstante, Cortés supo muy bien a quién escribía y cómo, de la mano de su redacción, se jugaba su destino terrenal: resultaría héroe o traidor. Todo estaba puesto allí sin titubeos: debía mostrar su valor, don de mando, diplomacia, juicio práctico, lealtad, compromiso con la Iglesia y la evangelización y, por sobre todas, su servicio a la Corona. Por tanto, todos sus esfuerzos retóricos, cuando así los requirió, se empeñaron en demostrar que él perseguía una causa superior que tal vez ni siquiera habría rogado encabezar y que, poniéndolo las circunstancias divinas de tal modo, él no tenía más remedio que obedecer a Dios por encima del gobernador Velázquez, Narváez o el propio rey español. Sin embargo, como se ha demostrado, Cortés también reveló el problema que se ha evidenciado desde el principio: dónde termina la providencia humana y dónde comienza el libre arbitrio del hombre; si es que ambos empiezan o terminan en alguna parte o coexisten, y de ser así, en qué proporción o niveles. Este dilema teológico quedó manifestado cuando, por una parte, exploró en el Cielo razones sobre un inesperado éxito militar en 1520 que lepermitió,, incluso, encarcelar y luego asesinar al máximo tlatoani y, por otra, admitió haber actuado por su cuenta y riesgo: determinó dejar un contingente en tal lugar, fundar una villa, castigar al insurrecto, etcétera. Pero, sobre todo, decidió no recular sino rearmarse y emprender de nuevo su camino a Tenochtitlán después de la Noche Triste. La frontera que hay entre qué decide Dios y cómo lo hace saber a sus elegidos es tan difusa o incomprensible, como saber cuándo el hombre obra por sí, obedeciendo un supuesto llamado de lo alto o la misteriosa conjunción de ambas acciones: yo decido porque Otro está atrás apuntándome el camino.

Si seguimos a Tomás de Aquino, Cortés compartió el «honor de la causalidad» pues Dios le favoreció para ser «segunda causa» de acciones transformadoras; sin embargo, el providencialismo tomista miraba al futuro, lógica en la cual Cortés, antes bien, actuó con imprudencia pues no ordenó algo adecuado a un fin sino que el fin vino a él y, siendo la prudencia mitad razón y mitad apetito, se dejó llevar por sus pasiones y desobedeció a sus autoridades. Al mismo tiempo, habría sido prudente porque preveía el futuro (la conquista) y era necesario escribir y pedir ayuda para el tramo final, como lo sospechaba. La Segunda revela, pues, una especie de sinsabor teológico; un reñir entre la voluntad divina y la humana. Y por supuesto, aquí no queda resuelto.

Por último, quiero llamar la atención sobre las exitosas maniobras de su retórica. Si bien no se puede afirmar que el documento careció de sinceridad en algunas partes, sin duda, para cuando despachó la Segunda, preveía ya que algo grande podía pasar si no bajaba la guardia y cuán importante era que en España se entendiese del mismo modo. Supo utilizar la inventio para persuadir, cuando menos, de que algún hecho histórico estaba por ocurrir pues, por otro lado, no podría saberse cuál sería la interpretación de la misiva (siquiera, si se 
hubiese conocido), si Cortés no hubiese logrado vencer con sus ejércitos a la ciudad de «Méxyco». Asimismo, logró afianzar bien su papel histórico ante los ojos y los oídos de la corte española, pues los lugares empleados no podrían haber sido más novedosos: era, en verdad, un mundo nuevo. $\mathrm{Si}$, en el mismo supuesto de que no se tuviese el triunfo, cuando menos con la carta, bien escrita y desarrollada, ya despertaba la curiosidad, la voracidad y el germen del poder sobre esas extrañas tierras en donde no conocían al Dios cristiano - antes bien, había «muchas mesquitas o casas de sus ídolos» (Cortés, 1993: 237)—, ni la seda, los caballos o la pólvora. Él, mejor que nadie, era garante de paz pues «proveyendo las cosas que parescia que convenían al servicio de Vuestra Sacra Majestad», pacificaba al tiempo que ganaba territorios y descubría minas (1993: 248).

A pesar de su gran difusión, una cédula real de marzo de 1527, mandó prohibir la impresión y lectura de esta y todas las relaciones de Cortés, lo que no mermó la ya bien construida imagen, para entonces y por siglos, de héroe más que digno de imitación.

\section{BIBLIOGRAFÍA CITADA}

Agudo Romeo, María del Mar (2000). «El providencialismo en la Cronica Actitatorum Temporibus Benedicti Pape XIII de Martín de Alpartir», Aragón en la Edad Media. 16, pp. 1-14.

Agustín, San (1988). La ciudad de Dios. Santos Santamarta del Río y Miguel Fuertes Lanero (trad.); Victorino Capanaga (intr. y notas). Madrid: BAC.

Aquino, Tomás de (1990). Suma de Teología Parte III. Emilio Calle Campo et al. (trad.). Madrid: BAC.

Aquino, Tomás de (1998). La Suma contra gentiles de T. de Aquino. Jesús M. Pla Castellón (versión). Madrid: Alianza.

Aracil Varón, Beatriz (2008). «El monarca, su vasallo y el otro: Hernán Cortés y los vínculos de la escritura», en Sonia Matalia, Pilar Celma y Pilar Alonso (ed.), El viaje en la Literatura Hispanoamericana: el espíritu colombino. Madrid: Iberoamericana, pp. 147160.

Aracil Varón, Beatriz (2009). «Hernán Cortés y sus cronistas: la última conquista del héroe», Atenea (Concepción). Revista de ciencias, artes y letras, 499, pp. 61-76.

Bodelón, Serafín (1997). «Orosio: una Filosofía de la Historia», Memorias de historia antigua. 18 , pp. 59-80.

Carmona Fernández, Fernando (1993). «Conquistadores, utopía y libros de caballería», Revista de filología románica. 10, pp. 11-29.

Castro, Américo (1987). Aspectos del vivir hispánico. Madrid: Alianza.

Castro y Castro, Manuel (1954). «El Hispanismo en la Obra de Paulo Orosio: Historiarum adversus Paganos libri VII», Cuadernos de Estudios Gallegos. 9, pp. 193-251.

Cayuela Cayuela, Aquilino (2008). ¿Providencia o destino? Ética y razón universal en Tomás de Aquino. Barcelona: Erasmus.

Cicerón (1999). Sobre la adivinación. Sobre el destino. Timeo. Ángel Escobar (trad. y notas). Madrid: Gredos. 
Contreras Peláez, Francisco José (2003). «El concepto de progreso: de san Agustín a Herder», Anales de la Cátedra Francisco Suárez. 37, pp. 239-269.

Cortés, Hernán (1993). Cartas de Relación. Ángel Delgado Gómez (ed.). Madrid: Castalia.

Delgado Gómez, Ángel (1993). «Introducción biográfica y crítica», en Hernán Cortés, Cartas de Relación. Ángel Delgado Gómez (ed.). Madrid: Castalia, pp. 9-72.

Díaz del Castillo, Bernal (1977). Historia verdadera de la conquista de la Nueva España, tomo I. Joaquín Ramírez Cabañas (ed. conforme a la de 1944). México: Porrúa.

Escobar Moncada, Jairo (2003). «Teología y cosmología en Platón», en Nelly Rodríguez Melo (ed.), Jornadas filológicas in memoriam Juozas Zaranka. Medellín: Universidad Nacional de Colombia, pp. 83-97.

Fernández, Aurelio (2003). Moral especial. Iniciación teológica. Madrid: Rialp.

Frankl, Victor (1963). «Imperio particular e imperio universal en las cartas de relación de Hernán Cortés», Cuadernos hispanoamericanos. 165, pp. 1-40.

Frost, Elsa Cecilia (1996). Este nuevo orbe. México: CECYDEL-UNAM.

Fuente, José Luis de la (1999). «La práctica de la utopía en la escritura de Hernán Cortés», Castilla. Estudios literarios. 24, pp. 21-44.

Hernández Lefranc, Harold (2006). «El trayecto de Santiago Apóstol de Europa al Perú», Investigaciones sociales. X, 16, pp. 51-92.

Lafaye, Jacques (1997). Mesías, cruzadas, utopias. El judeo-cristianismo en las sociedades iberoamericanas. Juan José Utrilla (trad.). México: FCE.

Márquez Villanueva, Francisco (1997). «El caso del averroísmo popular español (hacia La Celestina)», en Rafael Beltrán y José Luis Canet (ed.), Cinco siglos de Celestina: aportaciones interpretativas. Valencia: Universidad, pp. 121-132.

Martín Sánchez, María Angelita Fátima (1991). «Fatum y Providentia en Séneca», Taula, quaderns de pensament. 16, pp. 91-126.

Mendoza Negrillo, Juan de Dios (1973). Fortuna y providencia en la literatura castellana del siglo $X V$. Madrid: Real Academia Española.

Miralles, Juan (2001). Hernán Cortés, inventor de México. México: Tusquets.

Motto, Andrés (2004). «Severino Boecio y el sentido de la vida», Teología. 83, XL, pp. 7193.

Nauta, Lodi (2009). «The Consolation: The Latin commentary tradition: 800-1700», en John Marenbon (ed.), The Cambridge Companion to Boethius. Cambridge: University Press, pp. 255-278.

Prien, Hans-Jürgen (1996). «La justificación de Hernán Cortés de su conquista de México y de la conquista española de América», Revista complutense de historia de América. 22, pp. 11-32.

Sanguineti, Juan José (1985). «La filosofía del progreso en Kant y Tomás de Aquino», Anuario filosófico. XVIII/2, pp. 199-210.

Saranyana, Josep-Ignasi (2010). «Por qué De civitate Dei dio lugar a propuestas hierocráticas en el Medievo» en Pedro Roche Arnas (coord.), El pensamiento político en la Edad Media. Madrid: Centro de Estudios Ramón Areces, pp. 632-633.

Sellés, Juan Fernando (1999). «La virtud de la prudencia según Tomás de Aquino», Cuaderno de Anuario Filosófico. 90, Pamplona: Universidad de Navarra.

Séneca (1789). Los siete libros de Séneca. Pedro Fernández Navarrete (trad.). Madrid: Benito Caro.

Strosetzki, Christoph (1998). «El milagro en Calderón», en Manfred Tietz (ed.), Texto e imagen en Calderón. Undécimo Coloquio Anglogermano sobre Calderón (St. Andrews, Escocia, 17-20 de julio de 1996). Stuttgart: Steiner, pp. 240-253.

Tapia, Andrés de (2008). Relación de la conquista de México. México: Axial. 
Tate, Robert Brian (1994). «La historiografía del reinado de los Reyes Católicos», en Carmen Codoñer y Juan Antonio González Iglesias (ed.), Actas del Coloquio Humanista, Antonio de Nebrija: Edad Media y Renacimiento, celebrado en Salamanca 1992. Salamanca: Universidad de Salamanca, pp. 17-28.

Trigo, Tomás (2002). «Prudencia y libertad», Scripta theologica. 34, 1, pp. 273-307.

Vidaurre, Carmen (1996). «Acercamiento sociocrítico a la "Segunda carta de relación" de Hernán Cortés», Texto Crítico. Nueva época. 3, pp. 23-45.

Zavala, Silvio (1985). «Hernán Cortés ante la justificación de su conquista», Quinto Centenario. 9 , pp. 15-35.

Fecha de recepción: 2 de octubre de 2014.

Fecha de aceptación: 24 de abril de 2015. 